\title{
Abordagem teórico-prática sobre as condições ambientais e laborais de uma escola da rede municipal de Salvador-Bahia
}

\author{
Patrícia Farias Uchôa \\ Luiz Roberto Santos Moraes
}

\section{SciELO Books / SciELO Livros / SciELO Libros}

UCHÔA, P.F., and MORAES, L.R.S. Abordagem teórico-prática sobre as condições ambientais e laborais de uma escola da rede municipal de Salvador-Bahia. In: FERNANDES, R.C.P., LIMA, M.A.G., and ARAÚJO, T.M., comps. Tópicos em saúde, ambiente e trabalho: um olhar ampliado [online]. Salvador: EDUFBA, 2014, pp. 209-238. ISBN: 978-65-5630-012-2. https://doi.org/10.7476/9786556300122.0011.

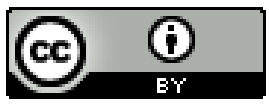

All the contents of this work, except where otherwise noted, is licensed under a Creative Commons Attribution 4.0 International license.

Todo o conteúdo deste trabalho, exceto quando houver ressalva, é publicado sob a licença Creative Commons Atribição $\underline{4.0}$. 


\section{Abordagem teórico-prática sobre as condições ambientais e laborais de uma escola da rede municipal de Salvador-Bahia}

Patrícia Farias Uchôa

Luiz Roberto Santos Moraes

\section{Introdução}

O quadro de agravo da saúde docente sinaliza uma preocupação com o futuro da educação e uma ameaça ao desenvolvimento da sociedade de forma sustentável. Percebe-se que não existe, nas instituições de ensino, o cumprimento da legislação vigente relacionada à Saúde e Segurança do Trabalho, denominada Lei $n^{\circ} 6.514$, de 22 de dezembro de 1977, que contempla as Normas Regulamentadoras (NR) de Segurança do Ministério do Trabalho e Emprego. (BRASIL, 2009) Vale ressaltar, entretanto, que a maioria das NR é desenvolvida com base nos limites necessários para a salubridade do ambiente de trabalho. A condição ideal de bem-estar do trabalhador, porém, deve estar condizente com as normas utilizadas no campo de estudo do Conforto Ambiental.

$\mathrm{Na}$ atividade laboral do professor, limites de tolerância estabelecidos pela NR15-Norma para Atividades e Operações Insalubres são limites inadequados para avaliar as condições de bem-estar do docente. (BRASIL, 2009) O trabalho docente requer atividade intelectual de ensino/aprendizagem. Vale ressaltar que os professores da rede municipal são regidos pelo estatuto do Regime Jurídico Único (RJU). A proteção da saúde no ambiente de trabalho é um dever Constitucional do empregador e do Estado e está definida como um direito social determinado pela necessidade de redução dos riscos inerentes ao trabalho, por meio 
de normas de saúde, higiene e segurança, de acordo com o Artigo $6^{\circ}$, inciso XXII, do Capítulo II da Constituição Federal de 1988. (BRASIL, 2009) Segundo a Portaria no 3.214/2009, do Ministério do Trabalho, as empresas públicas, os órgãos da Administração Pública direta e indireta, que possuam empregados regidos pela Consolidação das Leis do Trabalho-CLT manterão, obrigatoriamente, serviços de engenharia e medicina do trabalho, a fim de promover a saúde e proteger a integridade do trabalhador no ambiente de trabalho. (BRASIL, 2009) Estes serviços também devem ser adotados para a modalidade da relação de trabalho da Administração Pública direta sob Regime Jurídico Único com o objetivo de assegurar o cumprimento do referido dispositivo Constitucional ao estatutário.

Este capítulo visa tratar de questões relacionadas à avaliação das condições do ambiente laboral de uma escola municipal na cidade de Salvador-Bahia. Por meio de diversas estratégias metodológicas, a pesquisa realizada teve como objetivo apresentar um diagnóstico abrangente das condições do ambiente do trabalho docente nesta escola, considerando parâmetros normativos e citações de referências na área, tendo sido realizadas as seguintes atividades: análise das características da edificação e seu entorno, monitorização dos níveis de pressão sonora, temperatura e iluminação para fins de avaliação ambiental e ocupacional, formulários de anotações das atividades cotidianas e entrevistas complementares relacionadas à percepção dos fatores físicoambientais.

\section{Metodologia e resultados}

A metodologia e os resultados desta pesquisa estão apresentados em itens específicos sistematizados da seguinte forma:

- Seleção da escola objeto de estudo;

- Monitorização para fins de avaliação ocupacional;

- Monitorização para fins de avaliação ambiental;

- Percepção dos professores da Escola Brigadeiro Eduardo Gomes sobre as características do seu ambiente de trabalho.

Este estudo envolveu avaliações bem diversificadas e com metodologias específicas, normatizadas e extensas. As monitorizações envolveram fatores presentes nos ambientes de trabalho como ruído, 
temperatura e iluminação. Cada aspecto foi avaliado considerando-se especificidades e abordagens diferentes com base em parâmetros ocupacionais e ambientais.

Desta forma, o conteúdo coletado se apresentou complexo por abranger muitos dados. Assim, optou-se em apresentar os aspectos metodológicos de cada parâmetro avaliado, seguido dos resultados inerentes a cada item. Desse modo, a apresentação dos aspectos metodológicos adotados para análise de cada item, dos resultados obtidos no estudo e da comparação desses resultados com o que está estabelecido nas normas que regulamentam os ambientes de trabalho e a legislação ambiental estão apresentados em conjunto. Esse procedimento foi adotado a fim de proporcionar um entendimento mais direto, objetivo e adequado dos dados coletados e analisados.

\section{Seleção da escola objeto de estudo}

A seleção do objeto de estudo foi realizada a partir de análise de resultados produzidos por um estudo anterior, em 2006, orientado por professores do Departamento de Medicina Preventiva e Social da Universidade Federal da Bahia e do Núcleo de Epidemiologia da Universidade Estadual de Feira de Santana. Na análise realizada, foi utilizado questionário estruturado contendo informações sobre: características sociodemográficas, características gerais do trabalho docente, aspectos psicossociais do trabalho, condições do ambiente escolar e avaliação de possíveis efeitos sobre a saúde vocal, dentre outros. Para fins de selecionar o local deste estudo, foram analisadas as variáveis contidas no terceiro bloco do questionário que incluíam dados sobre ventilação, umidade, calor, acústica, ruído excessivo, ruído externo excessivo e luminosidade. Esses dados foram analisados com vistas a selecionar uma escola para a realização de avaliação ambiental e ocupacional. A análise foi feita após a seleção de uma Coordenadoria Regional de Educação (CRE) do município, dentre todas existentes.

A CRE selecionada foi a de número seis por ser esta a coordenadoria com o maior número de questionários aplicados aos professores da rede municipal, totalizando 533. Além disso, de acordo com dados fornecidos pela Secretaria Municipal da Educação, Cultura, Esporte e Lazer, a CRE 6 (Itapuã) possui o maior número de escolas (49 unidades), 
portanto, sendo a regional de Salvador com o maior número de escolas também. (SALVADOR, 2012) Para a escolha da escola a ser estudada foi utilizado como critério de seleção específico os resultados obtidos com a análise das variáveis descritas acima (relativas a ruído, temperatura e iluminação). Assim, depois de selecionada a CRE 6 (Itapuã), foi feita a seleção da escola com o maior percentual de queixas dos professores com relação ao seu ambiente e trabalho.

Com base nesses procedimentos minuciosos de seleção, em que foram avaliadas diversas características do ambiente escolar, a Escola Municipal Brigadeiro Eduardo Gomes da CRE 6 (Itapuã) se apresentou como a instituição de maior percentual de queixa referidas pelos professores da rede municipal.

\section{Características da edificação da escola Brigadeiro Eduardo Gomes e seu entorno}

A Escola Brigadeiro Eduardo Gomes (BEG) está localizada no bairro de São Cristóvão, entre duas vias de circulação intensa. Uma via é caracterizada como coletora I (Avenida Aliomar Baleeiro) e a outra é caracterizada como via local (Rua Lauro de Freitas). A zona de concentração de situação do lote é residencial, entretanto, seu entorno é caracterizado por uma zona de concentração de uso comercial e de serviços. As edificações que margeiam o lado Sul da edificação escolar possuem, em média, dois pavimentos e estão voltadas, em sua maioria, para o comércio e serviço local. A instituição de ensino selecionada é da modalidade fundamental II (6 a 9 a série) disposta em somente um pavimento; funciona nos turnos da manhã, tarde e noite e possui seis salas de aula. O muro que delimita o lote do terreno é todo em alvenaria e não possibilita visibilidade do interior da edificação.

Por estar situada em área inadequada, a Escola BEG sofre interferências do entorno urbano no ambiente da sala de aula. A proximidade do Aeroporto (ruído proveniente das aeronaves que passam com frequência durante o dia e em altura reduzida) e a localização entre duas vias de circulação intensa de veículos (ruído proveniente do trânsito e do comércio com edificações de baixo gabarito) são fatores agravantes para a configuração de um ambiente de ensino saudável. Existe, também, um 
terminal de ônibus no lado norte do entorno da edificação e a frequência de ônibus estacionados ou em movimento é constante.

Além da interferência do ruído urbano, as salas de aula possuem grande interferência do ruído proveniente da própria escola, pois ficam localizadas ao redor do pátio coberto e as paredes que dão para o pátio possuem aberturas horizontais, acima da lousa, para favorecer a ventilação cruzada. Isso dificulta o controle do ruído em sala de aula, principalmente, quando alguma turma fica sem professor no horário de aula. A Escola BEG contém seis salas de aula, diretoria, secretaria, uma cantina, dois banheiros, uma sala dos professores, uma sala de informática, uma sala de vídeo, uma biblioteca, um pátio coberto e uma quadra esportiva, em um pavimento (Figura 1).

A disposição das salas de aula é ao redor do pátio coberto e a quadra esportiva fica localizada próxima às salas, provocando interferências de ruído nas salas quando utilizada para aulas práticas de educação física. A quadra foi disposta na área poente do terreno. Ambientes como a sala de professores, biblioteca, sala de informática e sala de vídeo, entretanto, estão localizadas no fundo do lote (Figura 1), sofrendo interferências do poente e próximo da quadra. A sala 03 recebe, no período da tarde, incidência solar direta, na parede lateral voltada para a quadra. Esta sala, também, tem a sua acústica prejudicada devido ao ruído advindo da quadra em momentos de aula de educação física de outra turma. As salas 01, 02 e 03 recebem incidência da luz solar durante todo o dia, no inverno e em parte do equinócio (pela manhã). As salas 04 e 05 recebem incidência solar durante todo o ano, pela manhã. 
Figura 1 - Planta baixa da escola indicando acesso e localização das salas de aula.

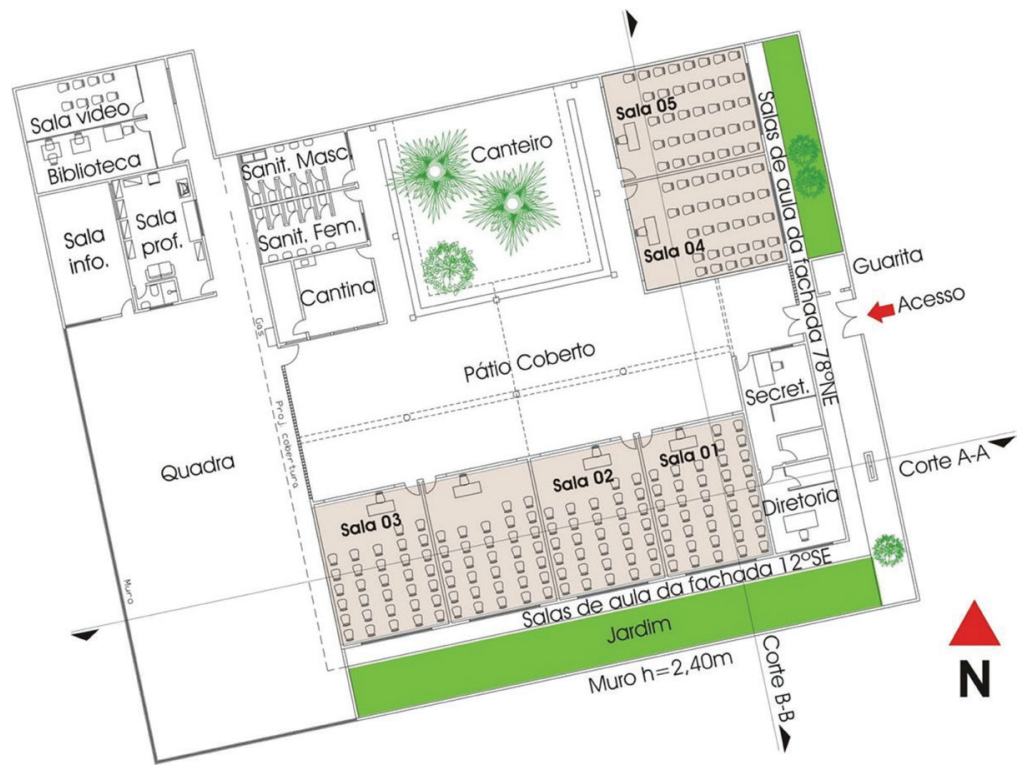

Fonte: (UCHÔA, 2009)

O edifício escolar possui laje coberta com telha em fibrocimento. As salas de aula estão dispostas, na maior parte, voltadas para a fachada $12^{\circ} \mathrm{SE}$. Não existe iluminação zenital na cobertura, o que contribuiria para a melhoria da iluminação em sala de aula. Entretanto, o nível de ruído aumentaria no momento da passagem das aeronaves, devido à proximidade de altura dos voos.

As salas de aula são padronizadas e possuem dimensões de $6,00 \mathrm{~m}$ x $8,00 \mathrm{~m}$, totalizando $48,00 \mathrm{~m}^{2}$. O edifício tem pé direito de $3,13 \mathrm{~m}$ com salas de aula com ventilação cruzada, por meio de janelas de correr com telas em aço nas fachadas e aberturas localizadas acima da lousa no lado oposto à janela. Cada sala possui dois ventiladores de parede giratórios localizados nas paredes laterais na altura de $2,30 \mathrm{~m}$ do piso. A abertura de entrada possui área maior que a abertura de saída do vento. O correto seria o inverso para aumentar a eficiência da ventilação.

As salas estão posicionadas a barlavento (região de onde sopra o vento em relação ao edifício) da edificação. Os ventos predominantes sopram em direção às fachadas $12^{\circ} \mathrm{SE}$ e $78^{\circ} \mathrm{NE}$, onde estão localizadas as janelas. 
A forma da edificação tem grande influência no conforto ambiental, visto que interfere diretamente nos fluxos de ar do interior e do exterior e, também, na quantidade de luz e calor recebidos pelo prédio. Esse aspecto tem sido desconsiderado, e são frequentes, por medidas de economia, coberturas de escolas com telhas de fibrocimento amianto que absorvem o calor e transformam as salas de aulas em verdadeiras estufas, motivo de frequentes queixas de alunos e professores. (RIBEIRO, 2004, p.110)

As salas de aula da Escola BEG são favorecidas pelos ventos Nordeste, Leste e Sudeste. Os ventos predominantes, entretanto, possuem dificuldade em adentrar a edificação da Escola devido à existência de um muro maciço limítrofe que circunda todo o lote da edificação e devido à existência de uma tela quadriculada, em aço, nas janelas das salas de aula. A posição e o tamanho das esquadrias na sala de aula, portanto, devem ser planejadas de forma a minimizar a propagação do ruído entre os ambientes internos da edificação. No caso da Escola BEG, as aberturas de saída de vento localizadas acima da lousa, contribui bastante para a interferência do ruído externo à sala de aula.

A dificuldade na criação de condições acústicas adequadas está, principalmente, ligada à localização das escolas, em geral próximas a vias movimentadas, à falta de recuo, à localização e tamanho de janelas das salas de aula e à localização das quadras de esporte. (BERTOLI, 2001) Além disso, as carteiras não apresentam proteção de borracha nos pés de ferro e por isso o atrito gerado com o piso da sala resulta em elevado nível de ruído. A durabilidade dessas peças de borracha é reduzida e logo as carteiras ficam danificadas.

\section{Monitorização para fins de avaliação ocupacional}

Após a análise das características da edificação e entorno da Escola BEG, métodos quantitativos foram utilizados para a monitorização do ruído, temperatura e iluminação. Nesta fase foram selecionadas cinco das seis salas de aula, considerando que as medições seriam feitas durante todo o dia em cada sala de aula, durante uma semana. A monitorização foi iniciada na segunda-feira (02/06/2008) pela Sala 01 e nos dias seguintes seguiu-se a ordem numérica: Sala 02 (03/06/2008), 
Sala $03(04 / 06 / 2008)$, Sala $04(05 / 06 / 2008)$ e Sala $05(06 / 06 / 2008)$ (Figura 1).

O período de monitorização foi de cinco dias úteis consecutivos por ser este considerado o ciclo de trabalho semanal do professor que se repete durante o mês de trabalho. Nesta etapa foi realizada a medição de ruído, temperatura e iluminação com a escola funcionando em cotidiano normal para avaliar as condições do ambiente laboral do professor em atividade. A cada aula concluída, era aplicado um questionário sobre situações relacionadas ao conforto térmico, acústico e lumínico. Como a Escola tem seis salas de aula e a semana só tem cinco dias úteis, uma sala de aula foi excluída da monitorização (a sala que não está com numeração na Figura 1) por possuir características muito semelhantes à Sala 2 já incluída nas medições (Figura 1).

Os equipamentos foram colocados na posição onde o professor passa a maior parte do tempo na aula, próximo à lousa e à mesa do professor.

As medições foram feitas com equipamentos específicos para avaliar cada fator ambiental do conforto térmico, acústico e lumínico e a calibração destes equipamentos foi realizada conforme os padrões de referência específicos. Foi utilizado um questionário adaptado, a partir dos instrumentos de outras pesquisas realizadas, elaborado com base nas Normas ISO 7.730 (1994) e ISO 10.551(1995).

As medições foram realizadas, simultaneamente (ruído, temperatura e iluminação), no período de uma semana (uma sala de aula em cada dia). A coleta de dados foi informada aos usuários da Escola, mas o tipo de equipamento e a variável de mensuração não foram informados detalhadamente a fim de não influenciar no comportamento dos alunos e na coleta dos dados.

Para avaliação do ruído foi utilizado o medidor de nível de pressão sonora digital modelo MSL-1.352C de marca Minipa. O medidor de nível de pressão sonora registra, de forma direta, o nível da pressão sonora de um fenômeno acústico.

A legislação brasileira, por meio de sua Norma Regulamentadora NR15 do MTE - Anexo A, estabelece que os níveis de ruído contínuo ou intermitente devem ser medidos em decibéis $(\mathrm{dB})$ com instrumento de nível de pressão sonora operando no circuito de compensação "A" e circuito de resposta lenta (SLOW). (BRASIL, 2009) Foi utilizado, 
também, um calibrador de nível sonoro MSL-1.336 da marca Minipa, que estava em conformidade com as Normas ANSI-1984 e IEC60.9422003 Classe 2.

Em relação ao ruído ocupacional, a monitorização foi planejada com base nas normas técnicas específicas para a atividade e o tipo de ambiente. As leituras devem ser feitas próximas ao ouvido do trabalhador. Assim sendo, a medição do nível de pressão sonora na escola foi realizada a partir do medidor de nível de pressão sonora digital, operando com estes parâmetros e intervalos programados de 10 em 10s. O importante era avaliar as salas de aula com seu cotidiano e funcionamento normal, portanto, não foram controladas as condições do ambiente. O medidor de nível de pressão sonora foi colocado no local onde o professor passa a maior parte do tempo, próximo à lousa e à mesa docente, na altura de $1,30 \mathrm{~m}$ do piso, considerando a altura média do campo de audição de uma pessoa. As distâncias determinadas foram de $1,00 \mathrm{~m}$ da parede do quadro e $2,90 \mathrm{~m}$ da parede lateral oposta à porta. Foi utilizada como referência a NBR 10.152 da Associação Brasileira de Normas Técnicas, 1987 que estabelece níveis de conforto em escolas entre 40 e $50 \mathrm{~dB}$ (sendo $40 \mathrm{~dB}$ o limite confortável e 50dB o limite aceitável).

O horário de medição foi de 07 h30 as 11 h50, considerando 1.465 valores analisados e de $13 \mathrm{~h} 30$ as $17 \mathrm{~h} 40$, considerando 1.405 valores analisados, totalizando 2.870 dados por dia.

A sala 04, monitorizada no dia 05/06/2008, não pode ser diagnosticada com maior precisão como as outras, considerando que só foi monitorizada em uma parte no turno da manhã e outra no turno da tarde, devido a realização de atividade pedagógica sobre o Dia do Meio Ambiente, a rotina da escola foi um pouco modificada em decorrência dessa atividade.

Foram calculados os níveis de ruído mínimo (Lmin), de fundo (L90), equivalente (Leq), esporádico (L10) e máximo (Lmax) em cada turno por dia de coleta. Foi possível identificar que os níveis de ruído variaram conforme o perfil da turma. Como cada turma foi submetida à medição durante um dia, foi possível comparar os níveis de ruído equivalente de cada uma. Os resultados mostraram que a sala 01 apresentou um nível de ruído mais elevado em relação às outras. As salas 02 e 03 são utilizadas por turmas de $7^{\mathrm{a}}$ e $8^{\mathrm{a}}$ séries (02) e $9^{\mathrm{a}}$ série (03), respectivamente. A faixa etária, portanto, influencia no comportamento e na 
geração do ruído. Já as salas 01, 04 e 05 são utilizadas por turmas de $7^{\mathrm{a}}(01)$ e $6^{\mathrm{a}}$ séries (04 e 05), respectivamente. As turmas da sala 01 são de $7^{\mathrm{a}}$ série nos dois turnos, entretanto, os professores, nas entrevistas nesta sala, ressaltaram o comportamento extremamente indisciplinado dessas turmas.

Foram calculados os mesmos níveis de ruído (Lmin, L90, Leq, L10, Lmax) por dia de coleta. O dia que apresentou situação mais crítica foi o dia 02/06/2008, porque o nível de ruído equivalente (Leq) foi de $86,4 \mathrm{~dB}(\mathrm{~A})$ e ultrapassou o valor de $85 \mathrm{~dB}(\mathrm{~A})$ estabelecido como limite de tolerância pela NR 15. (BRASIL, 2009) Além disso, este mesmo dia apresentou valor de $\operatorname{Lmax}$ de $116,7 \mathrm{~dB}(\mathrm{~A})$, considerado o mais alto dos valores referentes a esta medida estatística. O item 7 do Anexo 1 da NR 15 determina que as atividades que resultem em exposição de trabalhadores a níveis de ruído, contínuo ou intermitente, superiores a $115 \mathrm{~dB}(\mathrm{~A})$, sem proteção adequada, oferecerão risco grave e iminente. O nível de $116,7 \mathrm{~dB}(\mathrm{~A})$ encontrado nas mensurações está acima do limite de $115 \mathrm{~dB}(\mathrm{~A})$ da NR 15, o que caracteriza uma situação muito atípica. (BRASIL, 2009) Este diagnóstico de monitorização é mais frequente em situações ocupacionais de grave e iminente risco, existentes geralmente, em atividades industriais ou outras caracteristicamente ruidosas. Os alunos, por sua vez, estão expostos aos mesmos eventos de risco ambiental ocupacional. As vivências em salas de aula com ambientes ruidosos e com calor excessivo se comparam às condições existentes em galpões de linhas de produção industrial. O risco de perda auditiva começa a ser significativo a partir de um nível equivalente diário de 80dBA. (INSHT, s.d.) Não significa, entretanto, que uma pessoa não possa sofrer de perda auditiva exposta a níveis de ruído mais reduzidos. A exposição ao ruído está relacionada à susceptibilidade do indivíduo que está em atividade laboral.

O professor da Escola BEG, portanto, está submetido a níveis de ruído considerados inadequados para a realização da atividade laboral. O nível de exposição diário ao ruído deve ser mantido abaixo de $80 \mathrm{~dB}(\mathrm{~A})$. (INSHT, s.d.)

No caso da Escola BEG, os níveis de ruído equivalente ultrapassaram, durante todos os dias, o nível de $80 \mathrm{~dB}(\mathrm{~A})$. Isto significa que os professores estão expostos a níveis de ruído considerados danosos à saúde. 
Os níveis de ruído esporádico (L10) apresentaram valores um pouco acima dos níveis de ruído equivalente (Leq). Os níveis de ruído de fundo (L90) variaram de $67,6 \mathrm{~dB}(\mathrm{~A})$ a $71,5 \mathrm{~dB}(\mathrm{~A})$. Estes valores são considerados bastante elevados para a sala de aula. Portanto, para que seja mantida a diferença (sinal/ruído) de $10 \mathrm{~dB}(\mathrm{~A})$ entre o nível de fala e o ruído de fundo, a fim de que haja a inteligibilidade das palavras na sala de aula, é necessário que o professor aumente bastante o volume da voz para ser compreendido.

No estudo realizado por Bertoli (2001), levantando resultados das medições de Nível de Pressão Sonora (NPS) equivalente em 15 escolas estaduais, em três horários diferentes do dia, notou-se também que as fontes de ruído interno (próprios alunos, aparelho de ventilação) e as fontes de ruído externo (ruas ruidosas, pátio, corredores), são semelhantes em todas as escolas e a influência que elas exercem no aumento do NPS equivalente tem valores, aproximadamente, iguais.

Leucz (2001), com base em estudo realizado, traz a mensuração de ruído em quinze escolas selecionadas (cinco municipais, cinco estaduais e cinco particulares) e mostra que todas as escolas avaliadas revelaram resultados de nível de pressão sonora acima de $50 \mathrm{~dB}$, sendo este o nível limite estabelecido pela NBR 10.152 para o interior da sala de aula. (ASSOCIAÇÃO BRASILEIRA DE NORMAS TÉCNICAS, 1987) Os resultados de Nível de Pressão Sonora Equivalente - Leq variaram entre $62,5 \mathrm{~dB}(\mathrm{~A})$ a $77,5 \mathrm{~dB}(\mathrm{~A})$. O estudo, entretanto, não apresentou uma metodologia de mensuração detalhada e rigorosa. Cada sala de cada escola foi submetida a quatro pontos de medição para cálculo do Leq, e não foi apresentado o método de escolha destes pontos ou da sala selecionada para medição.

A pesquisa realizada por Eniz (2004) descreve as condições acústicas das salas de aula de escolas da rede pública e privada do Distrito Federal. Dentre as instituições avaliadas pela pesquisa, existe uma escola do ensino fundamental com as mesmas características que a Escola BEG, "prensada" entre duas avenidas movimentadas, com tráfego aéreo e terrestre intenso em sua vizinhança. O nível de pressão sonora equivalente, na escola semelhante à $\mathrm{BEG}$, foi de $82,7 \mathrm{~dB}(\mathrm{~A})$. Outros níveis observados foram: $\mathrm{Lmin}=46,6 \mathrm{~dB}(\mathrm{~A}), \mathrm{L} 90=64,4 \mathrm{~dB}(\mathrm{~A}), \mathrm{L} 10=86,5 \mathrm{~dB}(\mathrm{~A})$ e $\operatorname{Lmax}=106,8 \mathrm{~dB}(\mathrm{~A})$. A Escola $\mathrm{BEG}$, quando comparada à escola do estudo realizado por Eniz (2004), apresentou resultados semelhantes, 
o que confirma a situação crítica de edificações com este perfil avaliadas em outras pesquisas.

Em relação às medições de temperatura, a NR15 estabelece que estas devam ser realizadas no local onde permanece o trabalhador, à altura da região do corpo mais atingida. (BRASIL, 2009) Para a avaliação do conforto térmico foram utilizados: um tripé, o termômetro de globo modelo TGD-200 da marca Instrutherm e um anemômetro de palhetas designado termo anemômetro digital modelo MDA-11 da marca Minipa (para mensurar a velocidade do ar). Neste último, foi configurada a opção modo média $2 / 16 \mathrm{sec}$ para obter o valor médio de vento a cada 2 segundos. As situações estáveis das salas de aula foram: janelas abertas e iluminação artificial acionada durante todo o período de medição.

O tripé possibilitou determinar a altura ideal do equipamento para o objetivo do estudo. O termômetro de IBUTG foi colocado na posição onde o professor passa a maior parte do tempo na aula, próximo à lousa e à mesa, na altura do tronco, a 1,20m do piso. Por meio deste equipamento, foi medido, também, o IBUTG (Índice de Bulbo Úmido e Termômetro de Globo). Esta medição foi realizada a fim de investigar a exposição ao calor, considerando os limites de tolerância conforme o tipo de atividade e o regime de trabalho do professor. Os procedimentos desta avaliação foram estruturados a partir de orientações da Norma Regulamentadora Atividades e Operações Insalubres-NR15. (BRASIL, 2009) Por meio do índice IBUTG é possível estabelecer limites de tolerância para exposição ao calor, de acordo com taxa de metabolismo - Quadro 2 do Anexo 3 da NR15 - e o tipo de atividade de cada indivíduo - Quadro 1 do Anexo 3 da NR15. (BRASIL, 2009) Segundo a NR15 (BRASIL, 2009), o IBUTG é um índice de avaliação de exposição ao calor, não considerado parâmetro para conforto térmico, e sim, para tolerância a temperaturas extremas.

De acordo com o Quadro 3 do Anexo 3 da NR15 foi considerado o tipo de atividade moderada, especificamente, de pé, trabalho leve, em máquina ou bancada, com alguma movimentação (taxa de metabolismo de $220 \mathrm{kcal} / \mathrm{h}$ ). (BRASIL, 2009) De acordo com o Quadro 2 do Anexo 3 da NR15 para esta taxa de metabolismo requerida, o IBUTG máximo deve ser de 26,7. (BRASIL, 2009) Este método, geralmente, é utilizado para atividades de sobrecarga térmica (ambientes muito quentes com taxas metabólicas altas), portanto, esperou-se que os valores levantados 
fossem abaixo dos limites determinados pela NR15, considerando que estes dados são elevados para serem utilizados como parâmetros de referência no ambiente escolar. (BRASIL, 2009) Os dados foram registrados de 30 em 30 minutos por ser a temperatura uma condicionante ambiental com variações mais homogêneas. Além desse equipamento, foi utilizado o anemômetro térmico ou anemômetro de palhetas para medir a velocidade do ar. $\mathrm{O}$ anemômetro também ficou na mesma altura, próximo à mesa de trabalho do professor e foi locado a sotavento da sala de aula, o lugar menos ventilado, considerando ser o local onde o professor passa a maior parte do tempo. Por ser uma variável em que as questões subjetivas influenciam, durante as medições, foram aplicados questionários sobre as características físicas e percepção térmica dos usuários, a exemplo de idade, altura, sexo, tipo de vestimenta e sensação térmica. No questionário, também, foram incluídas questões relacionadas à percepção do conforto acústico e lumínico. Os questionários foram aplicados somente com o professor que tivesse em atividade laboral, no ambiente da sala de aula, no momento das medições.

As salas de aula mensuradas na avaliação para fins ocupacionais apresentaram resultados expressivos em relação ao conforto térmico. Como estas medições foram realizadas com a escola em funcionamento normal, o ambiente apresentou condições físicas variáveis. Foram coletados 76 dados por dia, totalizando 380 dados na semana de coleta. As variáveis coletadas foram: Tg (Temperatura de Globo), Tbs (Temperatura de Bulbo Seco), Tbu (Temperatura de Bulbo Úmido), IBUTG (Índice de Bulbo Úmido e Termômetro de Globo). A velocidade do vento foi coletada, entretanto apresentou resultados zerados em quase todo o período de coleta, por isso, esta variável foi considerada nula para os cálculos dos índices de conforto térmico. Em relação ao limite de conforto estabelecido pela ISO 7.730 (1994), o índice PMV (Predicted Mean Vote ou Voto Médio Estimado) apresentou a maior parte dos valores, durante todos os dias de medição, acima de 0,5. Quando analisado o limite adaptado para o clima quente e úmido por Lyra (2007), os valores continuam acima do limite de 0,9 , entretanto, reduziu o período de desconforto térmico.

Os dias 02, 03 e 04 apresentaram índices acima do limite de conforto durante todo o período de medição. $\mathrm{O}$ valor mais alto identificado foi de 
2,0 no horário de 10 h00 do dia 02/06/2008. O menor valor foi de 0,22 às 8 h00 do dia 06/06/2008.

Em relação ao índice PPD (Predicted Percentage of Dissatisfied ou Percentagem de Pessoas Insatisfeitas) quase todos os valores se apresentaram acima do ideal de $10 \%$ de usuários insatisfeitos, segundo a ISO (International Organization for Standardization) 7.730 (1994). O percentual mais alto calculado com base nas variáveis coletadas nos cinco dias foi de $76,7 \%$ com PMV correspondente de 2,0 e o valor mais baixo foi de 6,0\% com PMV correspondente de 0,22.

$\mathrm{O}$ índice PET (Physiological Equivalent Temperature ou Temperatura Fisiológica Equivalente) apresentou todos os valores acima da faixa de conforto recomendada por Hoppe (1999) de 22 a $24^{\circ} \mathrm{C}$ e acima da faixa de conforto adaptada por Lyra (2007) para clima quente e úmido de 22 a $26^{\circ} \mathrm{C}$. O menor valor foi de $26,6^{\circ} \mathrm{C}$ às 8 h00 de $02 / 06 / 2008$ e o maior foi de $30,7^{\circ} \mathrm{C}$ às 10 h00 de 06/06/2008.

O índice IBUTG coletado apresentou todos os valores dentro da faixa limite de 26,7 - estabelecida pela NR15 para este tipo de atividade. (BRASIL, 2009) O maior valor foi de 26,4 , às 8 h00 de 02/06/2008 e o menor valor foi de 23,6 às 7 h30 e 8 h00 de 06/06/2008. O índice IBUTG, na presente pesquisa, apresentou todos os resultados abaixo do limite estabelecido pela NR15, entretanto apresentou um resultado de 26,4 , às 11 h00 do dia 02/06/2008, considerado bem próximo do valor limite de 26,7. (BRASIL, 2009) Isto significa que o ambiente está próximo de ser caracterizado como insalubre, segundo a Norma citada.

O índice de temperatura efetiva, ao longo da semana de medição, apresentou-se acima da faixa de conforto recomendada pela NR17. (BRASIL, 2009) $\mathrm{O}$ valor calculado mais alto foi de $26,67^{\circ} \mathrm{C}$ e o menor valor foi de $23,33^{\circ} \mathrm{C}$. Não houve nenhum momento em que os dados calculados se localizassem dentro da faixa de conforto da norma (de 20 a $23^{\circ} \mathrm{C}$ ). Segundo os parâmetros da NR17, o ambiente avaliado dispõe de condições inadequadas de conforto. (BRASIL, 2009)

Os índices relacionados ao conforto térmico apresentaram, nesta pesquisa, resultados acima das faixas ou limites determinados pelas cinco referências citadas: ISO 7.730 (1994), NR 15, NR 17, Hoppe (1999), Lyra (2007).

O dia $02 / 06 / 2008$ foi o que apresentou os valores mais altos, tanto em relação aos índices de conforto térmico, como em relação aos 
parâmetros acústicos. Os resultados elevados da monitorização do calor deste dia podem justificar o comportamento agitado dos alunos, além de se tratar da turma avaliada como a mais indisciplinada, considerando que estes se encontravam em situação de bastante desconforto em sala de aula. Esta alteração de comportamento gerou um nível de ruído mais elevado também.

Para a mensuração da iluminação foi utilizado o luxímetro digital modelo LD-590 da marca Icel que ficou localizado na mesa de trabalho do professor. De acordo com a Norma Regulamentadora de Ergonomia NR17 da Portaria n $3.214 / 2009$, a fotocélula deste equipamento é corrigida para a sensibilidade do olho humano. (BRASIL, 2009) O equipamento foi configurado na escala 2.000lux. O fator iluminação também não tem variações grandes num mesmo ponto, entretanto, foi possível verificar, ao longo do dia, qual a variação de iluminação na mesa de trabalho do professor, posto ser considerado um local que requer apuração visual para atividades de leitura, correção de exercícios e esclarecimento de dúvidas em sala de aula.

Os níveis de iluminação natural foram comparados aos de iluminação média recomendados pela NBR 5.413 - Iluminância de Interiores, para salas de aula com usuários com idade inferior a 40 anos, onde a velocidade e precisão são importantes e onde a refletância da tarefa está entre $30 \%$ e 70\%. (ASSOCIAÇÃO BRASILEIRA DE NORMAS TÉCNICAS, 1992) Quanto aos índices de iluminação adotados neste estudo, dadas às características do observador e da tarefa, correspondem a 500lux para a lousa e 300lux para a sala de aula a serem medidos na mesa do professor. As medições de iluminação foram configuradas para intervalos de 5 em 5 segundos e o horário de medição foi de 7 h30 às 11 h50 e 13 h30 às 17 h40. Na medição da iluminação para fins de avaliação ocupacional, as luzes da sala ficaram acesas durante todo o período das medições, pois as aulas foram dadas com uso de iluminação artificial durante todo o tempo.

Os valores coletados no turno da manhã foram de 3.121 e no turno da tarde de 3.002. As iluminâncias médias, nas salas de aula, permaneceram com resultados acima da média de 300lux estabelecida pela NBR 5.413. (ASSOCIAÇÃO BRASILEIRA DE NORMAS TÉCNICAS, 1992) Entretanto, houve alguns momentos em que, mesmo com a luz artificial, os níveis de iluminância foram inferiores a 300lux. No dia 
05/06/2008, no período de 2 horas e 40 minutos a partir de 07h30, os valores variaram de 118 a 299lux. Isto significa que, mesmo que os resultados de iluminância média estejam acima do limite de 300lux recomendado pela NBR 5.413, existiram momentos da medição em que os níveis de iluminância apresentados foram abaixo do valor da Norma. (ASSOCIAÇÃO BRASILEIRA DE NORMAS TÉCNICAS, 1992) As salas 04 e 05, monitorizadas em 05/06/2008 e 06/06/2008, respectivamente, apresentaram condições de iluminação mais precárias nos dois turnos.

Quando apresentados os resultados das médias diárias de iluminâncias das salas em cada dia, observou-se que os dias 05/06/2008 (sala 04) e 06/06/2008 (sala 05) apresentaram as médias mais baixas. A sala 03, monitorizada em 04/06/2008 apresentou média de 571,22lux, sendo o maior valor e a sala $05(06 / 06 / 2008)$ apresentou média de 324,50lux, sendo o menor valor.

As salas pesquisadas, com orientação $78^{\circ} \mathrm{NE}$ (sala 04 e sala 05) como dito anteriormente, só recebem incidência do sol durante a manhã. Entretanto, mesmo no período da manhã, a vegetação e o muro presentes na frente das janelas interferem bastante na iluminação. A sala 01, como as salas 04 e 05, também apresentou níveis de iluminância mais baixos, entretanto, esta sala apresentava luminárias incompletas. A medição, com a sala de aula em funcionamento, foi realizada durante o dia e com as luzes acesas, observando-se os níveis de iluminância acima do valor recomendado pela NBR 5.413. (ASSOCIAÇÃO BRASILEIRA DE NORMAS TÉCNICAS, 1992)

Quando iluminadas artificialmente durante todo o dia, as salas de aula apresentaram resultados conformes aos requisitos estabelecidos na norma. Uma medida econômica a ser adotada é a opção do professor de ligar somente as lâmpadas da frente (parte mais prejudicada pela iluminação natural) e os assentos próximos às janelas seriam servidos somente pela luz natural. O edifício, portanto, foi projetado para funcionar com iluminação artificial durante o seu funcionamento. Os gastos com energia elétrica são altos e se transformam em custos inativos para o mantenedor da Escola. 


\section{Monitorização para fins de avaliação ambiental}

As medições deste período foram feitas nos dias 30/06/2008, 01/07/2008 e 02/07/2008 (segunda, terça e quarta-feira, respectivamente) por serem dias da semana normais - com exceção do dia 02/07/2008 que foi feriado local. Esta preocupação se deu para que fosse mensurado o ambiente da Escola com as características de funcionamento normal do entorno, sendo possível comparar também (o nível de ruído) com um dia atípico de feriado.

Como a escola se encontrava vazia, foi possível a mobilidade e precisão no deslocamento dos equipamentos sem maiores transtornos, devido à marcação prévia dos pontos com fita adesiva nas duas salas monitorizadas. As medições eram realizadas simultaneamente. Os equipamentos foram colocados de forma a mensurar os fatores ambientais na sala de aula. Foram selecionadas duas salas de aula padrão, com orientações distintas, para fazer uma medição alternada da temperatura, ruído e, quase simultânea da iluminação. As medições foram realizadas em duas salas selecionadas com orientações de fachada diferentes. As salas selecionadas foram: salas 02 e 04 (Figura 1), sendo as medições iniciadas pela sala 02 .

A medição do nível de pressão sonora foi realizada, a partir do medidor digital modelo MSL-1.352C de marca Minipa, utilizando-se as condições sugeridas pela NBR 10.152 da Associação Brasileira de Normas Técnicas (1987), operando no circuito de compensação "A" e circuito de resposta rápida (FAST) e os intervalos programados foram de $5 \mathrm{~s}$ em $5 \mathrm{~s}$. Além disso, este modo operativo fornece o valor de pico do nível de pressão sonora e apresenta medições mais representativas em situações de características dinâmicas como voo baixo de aeronave em alta velocidade. Como a escola estudada está sujeita a este tipo de interferência ruidosa (ruído aeronáutico) por estar localizada no raio de proximidade do Aeroporto, na medição para fins de avaliação ambiental com a edificação vazia foi determinada a adoção do modo FAST, utilizado para diagnosticar as interferências do ruído urbano no edifício.

A metodologia foi elaborada, portanto, com base na NBR 10.151 da Associação Brasileira de Normas Técnicas (2000) e no documento de Procedimentos Específicos de Medição de Ruído Ambiente do Instituto do Ambiente de Portugal. (PORTUGAL, 2003) As posições 
de medições devem situar-se pelo menos a $1 \mathrm{~m}$ das paredes ou outras superfícies refletoras, a 1,5m das janelas e portas e entre $1,2 \mathrm{~m}$ a $1,5 \mathrm{~m}$ acima do solo. A NBR 10.151, determina uma distância de no mínimo $1 \mathrm{~m}$ de quaisquer superfícies, como paredes, teto, pisos e móveis. (ASSOCIAÇÃO BRASILEIRA DE NORMAS TÉCNICAS, 2000) As medições foram efetuadas em condições normais de uso do ambiente com janelas abertas, segundo a NBR 10.151. (ASSOCIAÇÃO BRASILEIRA DE NORMAS TÉCNICAS, 2000)

De acordo com os dois documentos, as medições em interior devem ser selecionadas considerando, no mínimo, três pontos distintos, afastados entre si, no mínimo $50 \mathrm{~cm}$. Segundo o Instituto do Ambiente (PORTUGAL, 2003), o resultado deve ser a média logarítmica dos valores obtidos nos três pontos. O equipamento foi locado a $1,50 \mathrm{~m}$ do perímetro da sala de aula, com distância entre os três pontos de $3,39 \mathrm{~m}$ e altura de 1,2m do piso. As medições foram programadas a intervalos de $5 \mathrm{~s}$ e em modo de resposta FAST, segundo a NBR 10.152. (ASSOCIAÇÃO BRASILEIRA DE NORMAS TÉCNICAS, 2000)

A escolha do intervalo de tempo de medição deve permitir obter um valor representativo da situação a caracterizar. No limite, a sua duração pode coincidir com a duração de todo o intervalo de tempo de referência, correspondendo assim a uma medição em contínuo. No caso de não serem efectuadas medições em contínuo, recomenda-se que o intervalo de tempo de medição acumulado do conjunto de amostras obtidas seja, no mínimo, de 30 minutos e que cada amostra não seja inferior a 10 minutos, excepto quando a duração do ruído particular for inferior. Recomenda-se que a recolha de amostras para a obtenção do valor representativo tanto do ruído ambiente como do ruído residual seja repetida em, pelo menos, dois dias distintos. (PORTUGAL, 2003, p. 3, grifo nosso)

Foram postos três pontos em duas salas com localizações diferentes. No presente estudo foram coletadas amostras de 30 minutos em cada ponto de medição de cada sala de aula, de forma alternada (de uma sala para outra). Foi utilizada como referência a NBR 10.152 da Associação Brasileira de Normas Técnicas (1987) que estabelece níveis de conforto em escolas entre 40 e 50dB (sendo 40dB o limite confortável e $50 \mathrm{~dB}$ o limite aceitável). As medições foram feitas na ausência de chuva, ventos fortes e outras fontes sonoras atípicas. Segundo o CREA-BA (2005), o limite estabelecido pela Lei Municipal n 5.354/1998 é 
de $70 \mathrm{~dB}$ entre 7 h00 e $22 \mathrm{~h} 00$ e $60 \mathrm{~dB}$ no período intermediário. A OMS aponta que o volume ideal vai até $50 \mathrm{~dB}$. Em cada ponto foram coletados 349 dados totalizando 1.047 dados a cada hora e meia em cada sala, de forma alternada. Para apresentar os resultados, os dados foram tabulados e, posteriormente, calculados os níveis equivalentes de ruído (Leq) em cada período.

Durante cada dia, foram coletados 7.329 registros, totalizando níveis de ruído equivalentes a 57,29 dB (A) no dia 30/06/2008, $57,30 \mathrm{~dB}$ (A) no dia 01/07/2008 e 56,59 dB (A) no dia 02/07/2008. Calculado o Leq diário, envolvendo os dados coletados nas salas 02 e 04, os resultados apresentados sofreram uma variação quase imperceptível do dia 30/06/2008 para o dia 02/07/2008. O nível de ruído equivalente diário calculado teve quase o mesmo resultado nos dias 30/06/2008 e 01/07/2008. No dia 02/07/2008 o resultado do Leq diário teve uma leve queda em relação aos dias anteriores. Considerando que o dia 02/07/2008 é feriado referente à comemoração da Independência da Bahia, provavelmente o nível de ruído equivalente tenha sido reduzido porque os ruídos urbanos sofrem alterações. A frota de ônibus é reduzida, o comércio fecha as portas e o trânsito de pessoas na rua também diminui.

Os valores de Leq calculados ultrapassaram o nível de $40 \mathrm{~dB}(\mathrm{~A})$ (na condição de janela aberta) estabelecido pela NBR 10.151. (ASSOCIAÇÃO BRASILEIRA DE NORMAS TÉCNICAS, 2000) O elevado nível de ruído externo pode ser em decorrência dos eventos que ocorrem com frequência no entorno urbano como: passagem de aeronaves, carro de som, ônibus, helicóptero, caminhão, veículos de passagem, dentre outros.

A temperatura foi outra variável avaliada no edifício escolar sem ocupação. Para a avaliação da temperatura foi determinado um ponto central em cada sala de aula. Posteriormente, foram sendo anotados, em um formulário de observação intensiva, os valores das temperaturas de trinta em trinta minutos. Foram coletados dados de temperatura do ar ou de bulbo seco, temperatura de bulbo úmido, temperatura de globo e velocidade do ar. $\mathrm{O}$ anemômetro foi locado a $50 \mathrm{~cm}$ da abertura de entrada, localizada a barlavento, região de onde sopra o vento em relação à edificação, para que fosse possível considerar a melhor situação do ambiente. Para mensurar a temperatura, foram coletados, por dia, 
84 dados de variáveis relacionadas ao conforto térmico e estresse térmico, totalizando 252 dados coletados nos três dias. Dados de pressão de vapor e umidade relativa foram necessários para o cálculo dos índices de conforto térmico. Para calcular a pressão de vapor, foi preciso a pressão de saturação correspondente à temperatura de bulbo seco e a pressão de saturação correspondente à temperatura de bulbo úmido. Os índices IBUTG, PMV, PPD e PET foram avaliados com a escola vazia para avaliar quais as condições de conforto ambiental que o edifício dispõe como ambiente de trabalho. O IBUTG nesta fase foi calculado com o uso de fórmula específica apresentada na NR15. (BRASIL, 2009)

$\mathrm{O}$ índice PMV apresentou parte dos resultados acima da faixa de conforto estabelecida pela ISO 7.730 (1994) entre -0,5 e 0,5. Entretanto, segundo o limite adaptado por Lyra (2007) para o clima quente e úmido em estudo de dissertação de mestrado voltado para o ambiente escolar, os valores do PMV permaneceram, em grande parte, na faixa de conforto, apresentando desconforto térmico em um período menor. O valor máximo apresentado nos três dias foi de 1,12 e o valor mínimo foi de $-0,71$ - ambos fora da faixa de conforto térmico. É importante ressaltar que os valores de PMV situados dentro da faixa de conforto se apresentaram como aceitáveis, considerando que a edificação estava desocupada neste período de avaliação do ambiente e as temperaturas médias compensadas são mais amenas na época de junho e julho.

$O$ índice PPD referente ao percentual de pessoas insatisfeitas, também, apresentou a maior parte dos valores dentro da faixa de conforto, quando apenas $10 \%$ das pessoas se diziam insatisfeitas. O maior percentual de pessoas insatisfeitas foi de 25,80\% às $10 \mathrm{~h} 30$ do dia 02/07/2008. $\mathrm{O}$ valor do índice PMV correspondente a este valor de PPD foi de 0,99.

O índice PET apresentou grande parte dos valores fora da faixa de conforto térmico, conforme o parâmetro entre 22 e $24^{\circ} \mathrm{C}$, estabelecido por Hoppe (1999). Lyra (2007) adaptou a faixa para o clima quente e úmido e segundo este novo parâmetro, estabelecido entre 22 a $26^{\circ} \mathrm{C}$, grande parte dos valores foi incorporada pela faixa de conforto térmico. O maior valor apresentado foi de $27,2^{\circ} \mathrm{C}$, às $14 \mathrm{~h} 00$ do dia $01 / 07 / 2008$ e o menor valor foi de $23,2^{\circ} \mathrm{C}$, às 8 h30 do dia $30 / 06 / 2008$. Considerando-se o limite de Hoppe (1999) para o índice PET, grande parte dos valores se apresentou na região considerada inadequada para o con- 
forto térmico. Quando considerado o limite adaptado por Lyra (2007), alguns valores ainda se localizaram fora do valor limite.

Nos três dias de medição, as salas de aula atingiram IBUTG máximo de 24,9 às 14 horas do dia 30/06/2008 e o mínimo de 22,8 às 8 horas do dia 02/07/2008. Neste período de medição, portanto, não foi ultrapassado o valor limite para considerar a atividade insalubre. Os valores do IBUTG ficaram abaixo do limite determinado pela NR15. (BRASIL, 2009)

O índice de temperatura efetiva apresentou a maior parte dos valores acima da faixa de conforto recomendada pela NR17 nos três dias, nas duas salas de aula. (BRASIL, 2009) O valor mais alto calculado foi de $24,17^{\circ} \mathrm{C}$ e o menor valor foi de $22,78^{\circ} \mathrm{C}$. Para efeito de avaliação da NR17, portanto, a condição da sala de aula, considerando a melhor ventilação da sala, foi precária e atribuída como desconfortável. (BRASIL, 2009) O índice TE apresentou a maior parte dos resultados acima do limite recomendado pela NR17. (BRASIL, 2009) Este índice foi adotado neste estudo, exclusivamente, a fim de verificar se atenderia ou não à NR 17, considerando ser esta a única norma regulamentadora que determina recomendações de conforto, embora, segundo a literatura, este índice não seja o mais adequado e moderno para avaliação do conforto térmico de um ambiente, por não considerar outras variáveis que envolvem esta quantificação. (BRASIL, 2009)

As medições de iluminação foram realizadas em duas salas de aula de cada escola com mesmas dimensões entre si, entretanto localizadas com diferentes orientações. A Escola permaneceu com as luzes apagadas durante os horários de medição. Somente no horário de 18 horas, as luzes da sala de aula foram acionadas. A NBR 15.215-4 - Iluminação Natural / Parte 4: Verificação Experimental das Condições de iluminação Interna das Edificações / Método de Medição da Associação Brasileira de Normas Técnicas (2004), foi utilizada como parâmetro para a metodologia de mensuração da iluminação nas salas de aula. Segundo a Norma, para dimensionar a quantidade mínima de pontos a serem medidos no ambiente, deve ser calculado o índice do local (k) por meio de equação específica.

No caso da sala de aula da Escola Brigadeiro Eduardo Gomes, o comprimento da sala é de $8 \mathrm{~m}$, a largura é de $6 \mathrm{~m}$ e a distância vertical entre a superfície de trabalho e o topo da janela é de $1,5 \mathrm{~m}$, totalizan- 
do um $\mathrm{k}=2,29$. Segundo a Tabela 2 da NBR 15215-4, para $2 \leq \mathrm{k}<3$, a quantidade mínima de pontos requeridas deve ser de 25 pontos. (ASSOCIAÇÃO BRASILEIRA DE NORMAS TÉCNICAS, 2004) As medições foram obtidas em três dias, em cinco horários diferentes. As medidas foram obtidas em quatro pontos ao longo do mesmo afastamento (um metro) da janela e para sete afastamentos diferentes $(1,20 \mathrm{~m}$; $2,40 \mathrm{~m} ; 3,60 \mathrm{~m} ; 4,80 \mathrm{~m})$ totalizando vinte e oito pontos por sala. Foram medidas as duas salas em seis horários diferentes: 8, 10, 12, 14, 16 e 18 horas. Por não dispor de dois luxímetros para medições simultâneas em cada sala, as medições foram iniciadas em uma das duas salas medidas em cada escola aproximadamente dez minutos antes do horário estipulado, conforme método de Ghisi e Lamberts (1997). Após este intervalo de tempo, ou seja, no início do horário estipulado iniciavam-se as medições na outra sala. Para a medição, foi utilizado um luxímetro digital. As medições foram realizadas respeitando-se a ordem e distribuição dos pontos. Segundo a NBR 15.215-4, deve-se planejar a malha evitando pontos muito próximos às paredes, portanto, recomenda-se um afastamento mínimo de 0,50m. (ASSOCIAÇÃO BRASILEIRA DE NORMAS TÉCNICAS, 2004)

Nesta fase foi utilizado um formulário em formato de planta baixa onde foram anotados os valores (lux) dos 28 pontos de iluminação de cada sala. Foi selecionado um ponto no quadro da sala que foi medido antes da sequência de medições de cada sala. O ponto de medição foi colocado no centro do quadro. As medições do quadro foram feitas antes da medição dos pontos de cada sala. A fotocélula era colocada na vertical, direcionada para a parede oposta com janela, a fim de avaliar a qualidade de iluminação da área do quadro ao longo do dia com iluminação natural e artificial, no horário de $18 \mathrm{~h} 00$. O quadro tem dimensões de $2,20 \mathrm{~m} \times 1,05 \mathrm{~m}$ e se encontra na altura de $1,04 \mathrm{~m}$ da base inferior para o piso.

As salas apresentaram níveis de iluminância precários ao longo dos dias medidos quando avaliado nas condições de uso exclusivo da iluminação natural. As carteiras situadas nas filas intermediárias representaram o local de melhor qualidade de iluminação no decorrer do dia, com exceção dos horários de 16 e 18 horas.

A sala 02 apresentou, ao longo do dia, resultados mais conformes com o valor médio recomendado pela norma NBR 5.413. (ASSOCIAÇÃO 
BRASILEIRA DE NORMAS TÉCNICAS, 1992) A sala 04 apresentou grande parte dos valores abaixo do valor médio de 300lux e maior número de assentos com iluminação insuficiente para a atividade. $\mathrm{O}$ turno noturno funcionava por meio, exclusivo, da iluminação artificial, portanto, pode-se concluir que a condição de iluminação é precária considerando que os níveis, provavelmente, devem ser inferiores ao limite de 300lux estabelecido pela NBR 5.413. (ASSOCIAÇÃO BRASILEIRA DE NORMAS TÉCNICAS, 1992)

A iluminação da lousa ao longo de todo o dia de medição não atingiu o valor médio estipulado pela NBR 5.413 de 500lux nas duas salas de aula avaliadas. (ASSOCIAÇÃO BRASILEIRA DE NORMAS TÉCNICAS, 1992) Vale considerar que a referida Norma estabelece o limite para quadro negro, portanto, este valor deve ter sido determinado por esta, considerando a refletância de luz do quadro negro. A sala 04 possui iluminação bastante deficiente em relação à sala 02 , chegando ao valor máximo de 173lux no período dos três dias medidos, bem inferior à média de 300lux recomendada pela NBR 5.413 para salas de aula. (ASSOCIAÇÃO BRASILEIRA DE NORMAS TÉCNICAS, 1992) Essa diferença de iluminação ocorre, também, devido à presença de duas plantas altas e frondosas localizadas na frente da janela da sala 4. Existem, entretanto, outras condições que envolvem a avaliação do conforto luminoso.

Ghisi e Lamberts (1997) mensuraram salas de aula do Centro Tecnológico da Universidade Federal de Santa Catarina no dia 07 de junho de 1997 com o mesmo método utilizado neste trabalho. No estudo citado, as salas de aula orientadas para o Leste e o Sul tiveram seus valores variando entre faixas de 50 a 150lux no horário de 8 horas, 70 a 290lux no horário de 10 horas, 90 a 390lux no horário de 12 horas e 110 a 520lux no horário de 14 horas. Os pontos com iluminância mais baixos foram os pontos mais distantes da janela.

$\mathrm{Na}$ Escola BEG, os pontos mais distantes da janela apresentaram resultados abaixo de 300lux em todos os horários da medição e os pontos mais próximos tiveram níveis de iluminância altos na sala 02 e mais baixos na sala 04 .

A iluminação também é um fator ambiental que, quando apresentada de forma inadequada para a atividade a ser realizada no ambiente, gera problemas de saúde e prejudica a eficiência do ensino. Segundo 
Bormann (2003), valores de iluminância inferiores à 300lux tendem a gerar desconforto visual com prejuízo para a saúde dos olhos. A fadiga visual e cefaleias adquiridas em condições luminosas desapropriadas para a atividade laboral é resultado da dificuldade de acomodação da visão em decorrência dos ofuscamentos.

\section{Percepção dos professores da escola Brigadeiro Eduardo Gomes sobre as características do ambiente de trabalho}

A percepção dos professores sobre as características do seu ambiente de trabalho foram avaliadas a partir de questionários aplicados no período das medições, após cada aula ministrada em sala de aula. Os questionários foram aplicados no final da atividade laboral do professor para poder captar a percepção docente no momento de medição. A entrevista foi realizada ainda em sala de aula, antes que o professor se retirasse do ambiente avaliado. Foram cinco dias na semana (monitorização para fins ocupacionais) de entrevistas, cada dia monitorizando uma sala de aula e coletando as percepções dos professores que realizaram trabalhos no ambiente avaliado naquele dia. Os questionários foram aplicados após cada aula dada. Quando o professor dava duas aulas seguidas, os questionários foram aplicados após a última aula. Para avaliação de informações da população entrevistada, foram retirados do banco de dados os questionários aplicados para a mesma pessoa mais de uma vez, restando portanto, o total de 17 instrumentos aplicados para professores diferentes. Para as variáveis relacionadas à percepção do professor no momento da monitorização, foram considerados todos os instrumentos aplicados, mesmo que mais de uma vez para a mesma pessoa, configurando o total de 29 questionários aplicados. As entrevistas eram realizadas nas salas de aula, no momento da medição. Portanto, um mesmo professor, com as mesmas características biológicas estava sendo avaliado em momentos diferentes do dia, exposto a temperaturas e umidades diversas.

Em 02/06/2008, na sala 01 foi aplicado o maior número de questionários (9; $31 \%)$; seguido em $03 / 06 / 2008$ na sala 02 (7; 24,1\%); em 04/06/2008 na sala 03 (6; 20,7\%); e 06/06/2008 na sala 05 (5; $17,2 \%)$. 
Em 05/06/2008 obteve-se o menor número de questionários aplicados $(2 ; 6,9 \%)$ porque foi o dia em que teve o evento do Dia do Meio Ambiente, quando o número de aulas foi reduzido para a realização da atividade complementar. Os professores que participaram do estudo eram, em sua maioria, do sexo feminino, correspondendo a $15(88,2 \%)$ professores entrevistados. Em relação à idade, a faixa etária predominante foi de 30 a 40 anos com $8(47,7 \%)$ seguida dos acima de 40 anos. A média de altura, peso e idade foram de $1,62 \mathrm{~m}( \pm 0,087) ; 60,82 \mathrm{~kg}$ $( \pm 11,33) ; 38,71$ anos $( \pm 7,40)$, respectivamente.

Em relação ao conforto em sala de aula, 22 (75,9\%) professores referiram ter dificuldade de realizar o trabalho durante a aula. Quando questionados sobre o fator ruído na sala de aula, 22 (75,9\%) professores disseram que o ruído na aula incomodou. Ao serem perguntados sobre o tipo de ruído, $17(58,6 \%)$ afirmaram que foi o ruído da sala de aula que incomodou e $5(17,2 \%)$ disseram que foi o ruído de fora da sala de aula. Em relação às notas dadas para o conforto térmico, a menor nota foi 2 dada por $2(6,9 \%)$ professores e a maior nota foi $10 \mathrm{com} 1$ $(3,4 \%)$ resposta. A nota que teve maior número de indicação foi a nota 5 referida por $7(24,1 \%)$ professores. Em relação às notas dadas ao conforto lumínico, 8 (27,6\%) professores deram notas 7 e 8 . A menor nota dada foi a nota 3 por $1(3,4 \%)$ professor e a maior nota dada foi a nota 9 , também por $1(3,4 \%)$ professor. Estes dados contribuíram para uma avaliação mais integrada do ambiente laboral docente.

\section{Considerações finais}

A Escola Brigadeiro Eduardo Gomes não favorece ao conforto ambiental, em relação à sua localização e às características do edifício. A edificação escolar não está localizada em um lugar apropriado para o ensino, devido às interferências marcantes do ruído urbano. Do ponto de vista do conforto térmico, o terreno e o edifício apresentaram algumas considerações favoráveis, entretanto, o muro limítrofe (que serve de barreira acústica) impede o aproveitamento eficiente dos ventos predominantes. Foram encontradas situações críticas em relação ao conforto em sala de aula durante todo o tempo de avaliação do ambiente. As salas de aula são voltadas para um pátio coberto e possuem aberturas voltadas para este pátio, o que agrava a sua condição acústica. 
De acordo com a literatura, o nível encontrado de $116,7 \mathrm{~dB}(\mathrm{~A})$ torna-se extremo e requer uma atitude imediata de interdição da edificação escolar. A inviabilidade do uso de equipamentos de proteção individual descarta a possibilidade de continuação das atividades escolares. As condições acústicas encontradas na Escola Brigadeiro Eduardo Gomes representam situações graves, inadmissíveis e alarmantes diante dos parâmetros legais relativos aos limites de tolerância admitidos para a saúde do trabalhador. Crianças e jovens estão submetidos a ambientes danosos e ameaçadores à saúde humana. A não interdição indicaria o exercício das atividades de ensino nas salas de aula com níveis de Leq entre $80,6 \mathrm{~dB}(\mathrm{~A})$ e $86,4 \mathrm{~dB}(\mathrm{~A})$ e esta condição, em outras ocupações em situação ambiental semelhante pressupõe o uso de protetor auricular na realização do trabalho - o que seria inaceitável para a realização do trabalho docente. A realização de exames audiométricos para identificar possíveis perdas auditivas, é outra medida prevista na legislação trabalhista e que deveria estar sendo feita. Considerando, também, a necessidade de comunicação neste ambiente de trabalho ruidoso, existe a sobrecarga do aparelho fonador e isso agrava consideravelmente as condições de desenvolvimento de disfonias ocupacionais e outras patologias de natureza psicossomáticas associadas. (BEHLAU; MADAZIO; PONTES, 2001) Vale ressaltar que as mesmas indicações preventivas de uso de protetor auricular e realização de exames médicos são aplicáveis, também, para os alunos. Além disso, a necessidade de ação preventiva para níveis superiores à $80 \mathrm{~dB}(\mathrm{~A})$, segundo a NR 9, implica na indicação de medidas de ação para controle dos resultados aferidos neste estudo. (BRASIL, 2009)

A localização entre vias de movimento intenso, a proximidade do Aeroporto Internacional de Salvador, a utilização de equipamentos ruidosos em sala de aula e a estrutura espacial inadequada do edifício, favorecem bastante ao agravamento das condições acústicas precárias da escola BEG. Considerando que o ruído urbano interfere, consideravelmente, para o aumento do nível de ruído em sala de aula, devem ser tomadas medidas para minimização tanto do ruído interno, como do ruído externo.

A Escola não possui ambiente arborizado e o muro limítrofe da edificação impede a penetração de ventos. O local é ventilado, entretanto, a forma como foi concebida a edificação não favorece ao conforto 
ambiental. As condições de trabalho do professor são inadequadas à atividade laboral, visto que os resultados apresentaram valores acima dos limites de referência. O professor necessita de muito esforço da voz e da audição que entram em conflito com a utilização de recursos que amenizem o calor. Para utilizar o ventilador em sala de aula, o professor precisa aumentar ainda mais o seu tom de voz.

A partir dos dados coletados nesta pesquisa e suas análises, espera-se ter contribuído com os estudos em avaliação de ambientes laborais e estimular a construção de parâmetros para a melhoria do mesmo nas edificações escolares. Mensurar o conforto térmico é muito peculiar devido à vasta quantidade de variáveis envolvidas nesse processo. Foi possível identificar na pesquisa realizada que os índices nacionais e internacionais passam por constantes processos de aprimoramento. Apesar da atuação de grupos de pesquisa na área de conforto ambiental, é preciso fomentar o desenvolvimento de mais pesquisas que envolvam elaboração de índices mais modernos e precisos no Brasil. À pesquisa de Lyra (2007) é uma importante referência, mostrando que os índices internacionais podem estabelecer faixas de conforto térmico não adaptadas para a realidade do clima brasileiro. É preciso que sejam realizadas mais investigações sobre estes índices para que a utilização dos mesmos estabeleçam resultados mais concisos e confiáveis.

Em relação às medições das condicionantes ambientais, os valores apresentados, em grande parte, superaram os valores estabelecidos pelas normas de referências, com exceção do IBUTG, que por se tratar de um índice para avaliação de condições de estresse térmico possui limites considerados de tolerância ao calor e não de conforto térmico. Entretanto, mesmo nestas condições, o IBUTG atingiu o valor máximo de 26,4 em todo o período de medição.

Os valores limites ou faixa de conforto das condicionantes ambientais são regulamentados e normatizados de acordo com as políticas públicas de cada país. A edificação, quando avaliada isoladamente, apresentou níveis de ruído e iluminância bem insuficientes em relação aos valores preconizados pelas referências (nacionais e internacionais). O professor, submetido a este ambiente de trabalho, terá sua saúde prejudicada ao longo da vida laborativa.

Diversas limitações foram identificadas nesta pesquisa. Mensurar condicionantes ambientais é uma atividade muito complexa que re- 
quer muito planejamento, posto que estes fatores (ruído, iluminação e temperatura) sofrem variações significativas ao longo do dia e, portanto, precisam de um método sistemático para ser mensurados.

Em relação aos índices disponíveis para avaliação do conforto térmico, foi possível identificar que estes são consolidados por meio de normas que não dispomos no Brasil. Entretanto, é possível notar que, muitas vezes, esses índices não estão adequados ao clima brasileiro e, portanto, precisam ter seus valores adaptados para cada clima do País. Isso dificulta, relativamente, a elaboração e discussão dos resultados gerados nos trabalhos nacionais. Por isso, pesquisas estão sendo desenvolvidas para adaptar os índices internacionais aos climas de cada região do Brasil. Entretanto, ainda assim, foi possível observar que a percepção subjetiva dos professores confirmou os resultados quantitativos das monitorizações.

Como observado neste estudo, o ambiente da sala de aula e o processo de trabalho do professor não contribuem para a construção de relações participativas na escola, envolvendo os professores no gerenciamento e adequação dos ambientes e condições de trabalho. O espaço escolar carece de ambiente que possibilite atividades de ensino-aprendizagem não por meio de condutas legais (estabelecendo limites de tolerância), mas de condutas de promoção à saúde e favoráveis ao conforto ambiental. O estudante da geração atual necessita de um novo ambiente educacional, onde o professor é um colaborador no processo ensino/aprendizagem. É preciso que o professor esteja mais atuante nas questões relacionadas ao seu ambiente de trabalho, para que sejam realizadas propostas inclusivas no processo de melhoria das condições de trabalho docente.

\section{Referências}

ASSOCIAÇÃO BRASILEIRA DE NORMAS TÉCNICAS. NBR 10.151 (2000): Acústica - Avaliação do Ruído em Áreas Habitadas, Visando o Conforto da Comunidade. Rio de Janeiro, 2000.

. NBR 15.215-4 (2004): Iluminação Natural - Parte 4:

Verificação Experimental das Condições de Iluminação Interna de Edificações - Método de Medição. Rio de Janeiro, 2004. 
ASSOCIAÇÃO BRASILEIRA DE NORMAS TÉCNICAS. NBR 10. 152 (1987): Níveis de Ruído para o Conforto Acústico. Rio de Janeiro, 1987.

. NBR 5. 413 (1992): Normas para Iluminância

de Interiores. Rio de Janeiro, 1992.

BEHLAU, M.; MADAZIO, G. F. D; PONTES, P. Avaliação de voz. In: BEHLAU, M. (org. ). Voz: o livro do especialista.

Rio de Janeiro: Revinter, 2001. p. 85-245.

BERTOLI, S. R. Avaliação do Conforto Acústico de Prédio

Escolar da Rede Pública: O Caso de Campinas. In: ENCONTRO

NACIONAL, IV. , ENCONTRO LATINO-AMERICANO SOBRE

CONFORTO NO AMBIENTE CONSTRUÍDO, III. , 2001,

São Paulo. Anais... São Paulo: ANTAC, 2001. p. 1-8.

BORMANN, O. R. Iluminação natural em sala de aula e escritórios com uso de prateleiras de luz. Curitiba, 2003. 140f. Dissertação (Mestrado em Tecnologia) - Centro Federal de Educação Tecnológica do Paraná, Curitiba, 2003.

BRASIL. Ministério do Trabalho. Consolidação das Leis Trabalhistas, Decreto Lei 6. 214/1977 e Portaria 3. 214/1978 - Normas Regulamentadoras sobre Segurança e Medicina do Trabalho. Rio de Janeiro: Atlas, 2009.

CREA-BA. Barulho e monóxido de Carbono no Ar de Salvador. CREA-BA Revista, Salvador, 13. ed., out. /nov. /dez. 2005.

ENIZ, A. O. Poluição Sonora em Escolas do Distrito Federal. 2004. 111f. Dissertação (Mestrado em Planejamento e Gestão Ambiental) - Universidade Católica de Brasília, Brasília, 2004.

GHISI, E.; LAMBERTS, R. Avaliação das condições de iluminação natural nas salas de aula da Universidade Federal de Santa Catarina. In: ENCONTRO NACIONAL SOBRE EDIFICAÇÕES E COMUNIDADES SUSTENTÁVEIS, I. , 1997, Canela. Anais... Canela: ANTAC, 1997, p. 183-188.

HOPPE, P. The physiological equivalent temperature - a universal index for the biometeorological assessment of the thermal environment. International Journal Biometeorology, n. 43, p. 71-75, 1999.

INSHT. INSTITUTO NACIONAL DE SEGURIDAD E HIGIENE EN EL TRABAJO. Ruido. Espanha, s. d. Disponível em: <http://www.insht.es/ InshtWeb/Contenidos/Documentacion/TextosOnline/Guias_Ev_Riesgos/ Condiciones_trabajo_PYMES/cuestion13.pdf. > Acesso em: 27 jun. 2012.

INTERNATIONAL ORGANIZATION FOR STANDARDIZATION.

Ergonomics of the thermal environment - Assessment of 
the influence of the thermal environment using subjective judgement scales, ISO 10. 551. Genebra, 1995.

. Moderate thermal environments - Determination of the PMV and PPD indices and specification of the conditions for thermal comfort, ISO 7. 730. Genebra, 1994.

LEUCZ J. Ambiente de trabalho das salas de aula no ensino básico nas escolas de Curitiba. 2001. 60f. Dissertação (Mestrado em Engenharia de Produção) - Programa de Pós-Graduação em Engenharia de Produção, UFSC, Florianópolis, 2001.

LYRA, D. S. F. M. Aplicabilidade dos Índices de Conforto Térmico: Um Estudo de Caso em Salvador - Bahia. 2007. 131f. Dissertação (Mestrado em Engenharia Ambiental Urbana) - Escola Politécnica, Universidade Federal da Bahia, Salvador, 2007.

PORTUGAL. Ministério das Cidades. Ordenamento do Território e Ambiente. Instituto do Ambiente. Procedimentos específicos de medição de ruído ambiente. Lisboa, 2003.

OMS - ORGANIZAÇÃO MUNDIAL DE SAÚDE. Constituição da Organização Mundial de Saúde. Genebra, 1946.

RIBEIRO, S. L. Espaço Escolar: um Elemento (In) Visível no Currículo. Sitientibus, n. 31, p. 103-18, 2004.

SALVADOR. Secretaria Municipal de Educação, Cultura, Lazer e Esporte. Assunto: Educação em Números. Disponível em: <http://www.smec.salvador.ba.gov.br/site/educanumeros-escolas.php.> Acesso em: 10 jul. 2012. 